\title{
Thomas R. Lawson: Reflections on six decades of professional social work fundamental principles for social workers
}

What principles have I found to exist over my six decades of social work that are central to the profession and are still applicable in today's complex world? What has guided social work in its quest to address the myriad, ever changing and most difficult problems facing our societies irrespective of the continent or country? In my professional journey these practice guides can be synthesized into 13 basic principles that can serve as a strong foundation and are still highly useful today.

In my over 55 years as a professional social worker, studying the individuals and writers who were seminal to the profession to those who emerged during the mid- $20^{\text {th }}$ century, certain principles emerged. These principles arose from both practice and academic areas and have provided grounding and guidance that has led to the successful delivery of social work irrespective of the decade or location.

\section{BALANCE}

\section{Balance your learning between knowledge to do a job and knowledge for understanding}

In learning about social work, first in an academic setting and then continuing while you are in practice there must always be two goals in that learning process. Certainly, you have to learn what is needed to perform the functions of the particular job (workplace). There are rules, regulations, policies and specific duties you must perform and perform well. There are other things you need to know to be a really good social worker - this education is for understanding understanding social situations, the inter-relatedness of problems and the uniqueness of every individual. This knowledge can be applied across jobs. It is understanding at a deeper and more complex level and is not always applied in the same way to each case, rather it resides in you as a social worker to be used differentially with each client. Learning for understanding is what puts empathy and compassion into your work and connects you with each person individually. It is what makes the social worker unique in problem solving and defines us as different from other professions - to see solutions to problems not just in the rules and regulations of the job, or from a particular theoretical point of view, but in the integration of theory, rules and regulations to the specific individual who needs help. 


\section{ACCEPTANCE}

\section{Accept others and their differences}

One of the most important principles of social work is accepting others. Accepting them for what they are and what they can become. Realize that differences exist, and they exist for a reason for without differences there would be no world as we know it. There would be little to enjoy - little to experience. Imagine if every flower was a rose you would not be able to see the beauty that exists in the variety of flowers. Imagine if every person was the same you would not enjoy the exchange of different ideas, the variety of food different people eat, and the wonder of the diverse universe of individuals. Social work extols diversity, and as a social worker it is incumbent on you both in your work and life to be a model for accepting difference. It is your responsibility as a professional social worker to help others understand the beauty and wonder and indeed the value of accepting others that are different.

\section{COMMITMENT}

\section{To remain dedicated to helping others even when faced with difficult problems and situations}

Being a social worker is not a job or even a professional degree or certificate, it is a commitment within your soul to serve others and to be there when they need assistance. It is not like a uniform - something you take off at 5 o'clock during the week and put on the next morning, it is not something that you stop on Friday and start again on Monday. It is a lifelong commitment to others that undergirds the profession, it is that commitment to others to help them solve their life situations that defines the profession of social work and sets it apart.

\section{HUMANISM AND HOLISTIC}

\section{To see an individual as more than the sum of their parts and treat them with dignity}

As a social worker you are committed to both a humanistic and holistic understanding of people. The humanistic paradigm for social work is a belief system that views all people as having dignity, worth and the capability of self fulfilment. It is the belief that barriers hindering any individual from achieving their potential should be removed. You have to take into account the complete person and not just specific parts of the individual. You cannot simply look at an individual as a person who lost their job, you have to look at what else is happening in that person's life at the same time they are losing their job. You cannot look at a woman who is raising her children as just a mother but have to be very aware of those other aspects of her life, for example wife, or former employee are a part of her lived experience in this moment. You have to be 
committed to treating all with dignity no matter what their status, gender, orientation or religion, and you have to see each individual from their total life experiences.

\section{KNOW}

\section{Know your own strengths and weaknesses}

While social workers embrace the "strengths" approach in working with clients it must be recognized that the strengths approach has been adopted as a counter response to the long-used process of looking at weaknesses. A better approach is to not specifically focus on either strengths or weaknesses but to reframe the evaluation using different terms - assets the person has, assets they can obtain, and assets they are unlikely to obtain. These terms do not carry the polarity and also the pejorative connotation associated with weaknesses. Thus, they can be used to more appropriately determine how best to assist individuals, groups or communities as a social worker. Everyone has assets, assets they can obtain and assets they are not likely to obtain. For example, most social workers are better at the social sciences than the physical sciences and better with verbal activities than mathematical ones. Indeed, many social workers are not likely to obtain or want to obtain skills in math and physical sciences. Social science and verbal skills are assets that social workers have obtained while physical sciences and math are some they have not obtained or may not be easily obtained. If a social worker recognizes that physical sciences and math are not a part of their assets it might be a good to stop "batting their head against a wall" always trying to improve physical sciences and math. Instead, it might be better to focus on the assets they have and are more easily improved - social sciences and verbal abilities which are so very crucial in social work.

In social work there are certain clients a social worker can more easily work with than others - for example you can easily work with homeless people but cannot work well with people who have severe medical conditions. In such cases it might be better to recognize where you are better fitted (have the asset of working easily with that certain group) than to continue attempting to work with the group you are not as able to work with. The result is frequently a happier social worker and better client outcomes! Recognizing assets and lack of assets provides for optimal use of your time, skills and resources. That is not to say that you should not improve your assets, you should, but you should also "play to your assets" when possible.

There is a limited amount of time you have and often it is better to concentrate on assets and attainable assets and the principle is also absolutely true in working with clients. Clients have to recognize the assets they have, those they can obtain and those unlikely to be able to obtain. Helping someone to improve their education/training and find employment or learning ways to positively interact within their family and others (improving assets) are frequently activities social workers do daily. 


\section{TIME}

\section{Working on problems with will take time and effort - very few are solved immediately, and some are not solved at all}

As social workers we want to solve problems. We also want to solve them very quickly because we recognize that the solution will provide help for the person. But we have to recognize that some problems are not easily resolved, they have been there for a long time and often require a significant amount of time to amend. Other problems may not have been there for a long time but are so difficult or terrible that it takes quite a lot of time to resolve them. In social work you have to find a middle ground in working with people and problems. Some social workers after working with people for some years, experience "burn out". They have seen so many difficult problems and some that they have not been able to resolve they start to feel they cannot change anything and that they have to stop. They become resigned to not being able to help and that problems will always remain unchanged. Another common feeling of social workers now, particularly new social workers, is they must solve all problems and solve them immediately. The most successful social workers are in the middle of those positions. They realize that some problems are insoluble, and some problems can only be partially resolved. They realize what they can do and not do and accept the reality of the situation. They also realize that solutions are not always immediate, they require work on both the social worker part and the part of the individual or organization to effect change. It is important for social workers to "stay the course" when there is a solution but one that will only occur over a period of time. A recognition of the reality of time is a critical aspect of good professional social work practice. Furthermore, social workers must understand there is time for problem solving for others and time that you must take for yourself away from the profession. If you do not take time for "selfcare" - for time for yourself away from professional work, to refresh and rejuvenate and restore ultimately you will not be able to effectively help others.

\section{OBJECTIVE}

\section{To help individuals become objective in their perceptions of others and situations}

Not only do social workers have to be objective in their perception of others it is an essential part of professional practice to help clients become more objective in their perceptions of others and of situations as well. Many problems can often exist because the individual's view of the situation or another person is highly subjective and not founded in all of the facts. The teacher who always sees one student as the worst in the class and another student as the best, irrespective of the behavior or work of the student. A parent who always says their child is terrible when they are not always terrible. It is important for social workers to be neutral, to critically analyze the situation then help everyone involved to become more objective. For example, to help an 
employer see how the employee is not always making mistakes rather the problem is the poor quality of material and not the employee's performance. Another example occurs when a social worker is engaged in working with a couple where frequently the goal is to help both become more objective. You help them to realize that they are not always right and the other always wrong and to see that they are sometimes right and sometimes wrong and so is the other person.

\section{FOCUS}

\section{Continually focus on their situation as the foundation of their life and our relationship with them}

The key to working with people is to focus on the situation from "their" perspective. The old saying "you need to walk in the other persons shoes" could not be more applicable. A social worker should not begin with their own unchangeable view of the client's life - the starting point is the client's view of the situation and their life. It is how they see it that initiates the work - that initiates what is needed - that initiates how your relationship will develop into a helping one. Only by understanding how they view the world and what they see as the problem can you provide useful assistance even if that assistance is to help them to change that view. An old book on social work practice written over 60 years ago stated, "a social worker must start where the client is". Never were truer words spoken. You have to start with their perception of the problem and their world, even if it is a distorted view or misperception you must acknowledge it. First, acknowledge then help to clear misperceptions and distortions, do not immediately start to change them before establishing a relationship; to do otherwise will make it almost impossible to develop any relationship which is the foundation needed to resolve issues.

\section{UNIVERSAL}

\section{Recognize that human interaction is a universal phenomenon and one that transcends subject matter, institutions, culture and national boundaries}

As humans we always interact with others and that interaction is the basis for solving problems and helping. No matter where you are from or what you do, you interact. It may be in a different language, it may be in a different culture, it may be in a different religion and it may be from a different country but meeting and engaging is what we do. As social workers it is critical to our professional work. No matter what a person's background, status in life, or beliefs we are there as the example of what it means to put out the helping hand, to put out the hand of friendship and to put out the hand of caring. Ultimately people want to relate to each other - it may be difficult, and you may struggle with cultural differences, language barriers, religious beliefs, personality conflicts or physical problems and many other factors, but the professional social worker realizes that in order to complete the work of helping others it begins with relating. 


\section{TOGETHER}

\section{We must be united in our work}

Collectiveness is important to society, to individuals and to the profession. Solutions to many social problems are ones that need to be resolved systematically and not individually through societal change. Many problems, for example, poverty, discrimination and health are rooted in society and it is only through societal change they can be effectively addressed. Yes, you can spend a lot of important professional time helping to alleviate these problems for individuals one by one, but they will remain and never be significantly reduced across society, continuing to occur from generation to generation. If you are trying to assist a person who is unemployed to get a job when there is $20 \%$ unemployment in the community, there is a very small chance of employment. If the social worker adopts a systems viewpoint where jobs need to be created and individuals trained to do those jobs, that individual has a greater chance of obtaining work. Using the systems approach in such situations helps not only the individual you are directly working with but many other individuals who are part of the community. The social worker can be a part of the team to help to develop or bring in businesses, or projects that will employ more people - solving the problem on a scale larger than at the individual level. The profession needs to work at both the individual and societal level recognizing that most problems occur in both individual and also societal contexts.

We are experiencing obsolesce at a rate never imagined 30 years ago. New products and innovations frequently replace ones in use for 5 years or less. Social work must recognize that unemployment is inevitable in a specific job area or in a specific location if there is not a replacement for the current product or an innovative change for that product. How can the social worker help resolve these types of problems? We can anticipate them and work with the community to prepare for them. The social worker who recognizes that a new highway may bring more people into a community can help local officials to look at current unemployment and the skills of individuals and families they work with. They can help the community to create training for their unemployed clients so that they have the skills to meet the opportunities that the new highway provides.

If it seems that a product will no longer be produced, then what can social work do to foresee that situation and help the local people accept this change and prepare for it. What can the employees do to develop new skills and ways to adapt rather than to wait until something happens

and be "hurt" in the process rather than anticipating, preparing and being ready and not being adversely affected. It is in togetherness - togetherness of the social workers, individuals, community agencies, businesses and government that more effectively resolves problems. There is an old saying "United we stand, divided we fall!". 


\section{UNCERTAINTY}

\section{Transcend the need for certainty in life and assist others in seeing that uncertainty is part of the beauty of existence}

Life is a pathway of change and uncertainty. We never know the future - we can plan for it, but it is never totally sure. It is the nature of humans to want to try something new, to attempt the never tempted, to venture into the unknown, and to experience the never before experienced. We must adapt to uncertainty and change. As social workers we have to face uncertainty ourselves and help our clients face it. We can prepare but we can never be certain, we can hope but never be sure, we can expect but it may never happen. When we cannot predict the outcome, we still have to accept but we can work to make a change if the outcome is not one, we want. We have to be adaptable to change and we have to help our clients to be able to do the same. Everything changes no matter how much we do not want it to change. We age, we move, we lose friends, we find friends, we learn to do things and find that we cannot do some things we formerly were able to do. Facing uncertainly and preparing for the potential of many different outcomes is not saying whatever will be will be... No, it is making plans and developing a path.

\section{REALITY}

\section{Reality is contextual}

One person's reality may be another person's fantasy. While this is the extreme, the way we see things, the views we have, the ways we think and what we believe to be true or false or real or unreal may not be the same for another person. Every situation creates a reality, one that is interpreted differently depending on the person observing it. Imagine a family and what they might be thinking about a meal they are getting ready to eat. The person who cooked the meal may think of the meal and something they did for the family, how much work it took time to prepare, it is healthy and good to eat. The young child's reality may be that it is something they do not like, they do not care if it is healthy, or how much work it was to prepare and will try not to eat it. Another family member may see it as fattening and something to avoid while for another is it their favorite food and do not care if it is healthy, fattening or how it looks or the work that went into cooking the meal. It is the same meal and the same food but seen in a very different way and in a very different context depending on how each person has constructed their reality.

To state whether the glass is half empty and half full it is simply a matter of where you place your emphasis. You create the reality of the liquid - the reality is in what direction you make important. Do you want the glass empty so that you can dry it and put it away or do you want to fill it so that you have a full glass of water to drink? The same is true of interactions with others. People have all kinds of behaviors, beliefs and traits. We have to determine if we "see that person 
as half empty or half full" where is our reality. Do we say they are not good; someone we do not like or accept, or do we say they are someone we like and accept? Do you focus on the negative or the positive? What is the reality? Always remember to "check" your reality in your world view and with others.

\section{RESILIENCE}

\section{Social workers must have resilience and help the people they work with to also have resilience to keep on trying to improve and to solve problems}

You can compare life's journey as one that is similar to the performer on the trapeze. Most of the time you are able to swing free on the bar and perform well. However, sometimes you make a mistake, or something happens, and you are not able to hold onto the bar. When that happens there need to be two things below you. The first is a trampoline that you can hit when you fall. When you hit the trampoline, you bounce back up to be able to catch the bar again. The trampoline is like resilience, you bounce back up and start again. There are times when you fall and do not hit the trampoline, but you are caught in the safety net. The safety net helps you from really getting hurt and holds you securely until you can get on the trampoline. After a time in the safety net, you get on that trampoline and start to bounce higher and higher, up and up until once again you are able to grab that bar and swing fee on your own again

Resilience is like that; it is the ability to come back and to keep going even when you have a minor fall to the trampoline or a bigger one to the safety net. It is the willingness to start again, to get up and grab that bar again. Resilience must be part of you and part of your work. It also must be imparted to those you work with because it is the very essence of life's journey.

Today, social work in Hungary has already started its second generation. You have pioneers who have gone before and blazed a trail for the profession. They started with little and have achieved a lot. Those pioneers are leaving an important legacy, one that encompasses the principles found in this paper. It is now up to you, for those still out there from the first generation to continue that quest and for those just starting to take up the torch and keep that professional flame burning. The future ahead is always difficult, it is unknown, but it is a future that will have people always needing help. It is a future that provides huge challenges for all of us, but social workers always take up that challenge, they keep going when it is most difficult and are dedicated to make the life better for everyone everywhere. That is your charge, that is what you have chosen to do, it is the call from those needing help you hear, it calls you to respond - to make the world a better place. 